\title{
FLEXITEMPORALIDAD Y RÉGIMEN EXTINTIVO EN LOS CONTRATOS DE RELEVO E INTERINIDAD: RECTIFICACIÓN DEL TJUE Y MANDATO DIRIGIDO
}

\author{
Óscar Contreras Hernández \\ Profesor Ayudante de Derecho del Trabajo y de la Seguridad Social \\ Universidad de Castilla la Mancha
}

\begin{abstract}
La temporalidad en la contratación laboral en España y su uso irregular o abusivo sigue levantando ampollas; dos nuevas sentencias del Tribunal de Justicia de la Unión Europea (TJUE) dan buena prueba de ello y, aunque cierran algunas controversias surgidas a partir de la doctrina de Diego Porras, lo cierto es que abren otras. En este artículo se efectúa un comentario crítico de ambas resoluciones valorando algunos elementos clave sobre los que, no cabe duda, seguiremos hablando.
\end{abstract}

Temporary employment in Spain and its irregular or abusive use causes controversy. Two new decisions of the Court of Justice of European Union (CJEU) give a proof of that. Although they close some controversies arouse from the Diego Porras doctrine, others have been opened. A critical view of both resolutions is carried out in this paper. It analyzes and comments some key elements on which, no doubt, we will continue speaking.

Title: Flexitemporality and compensation regime in some temporary contracts in Spain: CJEU rectification and mandate directed.

Palabras clave: Principio de no discriminación, contratación temporal, extinción del contrato temporal, despido, indemnización.

Keywords: Non-discrimination principle, fixed-term contracts, compensation for extinction of the fixed-term contract, dismissal, compensation.

IUSLabor 2/2018, ISSN 1699-2938, p. 244-260.

DOI: 10.31009/IUSLabor.2018.i02.09 


\section{Sumario}

1. Planteamiento y antecedentes

2. Marco legal, controversias suscitadas y las resoluciones del TJUE

2.1. Asunto Grupo Norte Facility (C-574/16)

a. Los hechos enjuiciados

b. La respuesta a la controversia

2.2. Asunto Montero Mateos (C-677/16)

a. Supuesto de hecho

b. La respuesta del TJUE

3. Valoración de la fundamentación y sus efectos inmediatos

4. Conclusiones: la tormenta continúa

5. Bibliografía 


\section{Planteamiento y antecedentes}

La sentencia de Diego Porras, asunto C-596/2014, que considera contraria a la Directiva $99 / 70^{1}$ la norma española que deniega cualquier indemnización por extinción del contrato al trabajador interino mientras contempla la concesión de indemnización a los trabajadores fijos comparables, ha provocado en dos años un cisma interpretativo y aplicativo sin precedentes. Consecuencia lógica de su "catálogo de imprecisiones"2. $\mathrm{Saga}^{3}$, terremoto ${ }^{4}$, tormenta. Son solo algunas de las expresiones con las que la doctrina laboralista española ha calificado las reacciones y la masiva producción de interpretaciones, comentarios, análisis y resoluciones judiciales (divergentes).

Entre otros efectos, tanto esta sentencia, como las resoluciones de los casos Martínez Andrés, asuntos acumulados C-184/15 y C-197/15 y Pérez López, asunto C-16/15, concitaron a reflexionar sobre la validez del modelo de contratación temporal en España, evocando, una vez más, la necesidad de acometer una reforma legal en la materia. Sin embargo, la parálisis del legislador del momento, las declaraciones del presidente del TJUE manifestando que no entendieron bien el problema planteado en el caso Porras, las vicisitudes políticas posteriores ${ }^{5}$, y sobretodo, una resolución "técnicamente desafortunada" y que "abría más interrogantes de los que resolvía", invitaban a aplazar la ansiada intervención legislativa.

\footnotetext{
${ }^{1}$ Directiva 1999/70/CE del Consejo, de 28 de junio de 1999, relativa al Acuerdo marco de la CES, la UNICE y el CEEP sobre el trabajo de duración determinada. DOUE $n^{\circ} \mathrm{L}$ 175/43 de 10 de julio de 1999, en adelante, Directiva 99/70 o Acuerdo Marco.

${ }^{2}$ Molina NavarRete, C., El empleo temporal en el laberinto judicial: desenmarañando el enredo. Estudio de la doctrina judicial española aplicativa de la "trilogía" de Sentencias del TJUE de 14 de septiembre de 2016, Sepim, 2016, p. 32.

${ }^{3}$ Así la denominó el profesor RoJo TORRECILlA, E., a cuyo blog nos remitimos para un análisis amplio de los posicionamientos, evolución, reacciones e interpretaciones derivadas de los pronunciamientos del TJUE en la materia: http://www.eduardorojotorrecilla.es/2016/12/actualizacion-contratacion-temporaly.html.

${ }^{4}$ PEREZ REY, J, "Por una reformulación de nuestro modelo de contratación temporal: reflexiones sobre las consecuencias de la sentencia Porras en nuestro ordenamiento y la eficacia de la Directiva 99/70", Revista de Derecho Social, $\mathrm{n}^{\circ} 76,2016$, p. 229

${ }^{5}$ Con fecha 25 de mayo de 2018 como consecuencia de la sentencia condenatoria del Caso Gurtel se presentó por parte del secretario general del PSOE, Pedro Sánchez, una moción de censura en el Congreso de los Diputados que prosperó y provocó la destitución del hasta entonces presidente del Gobierno Español, Mariano Rajoy.

${ }^{6}$ Así, respectivamente, Gómez Abelleira, F. J., Contratos laborales y temporalidad. La política legislativa de contratación laboral, Tirant lo Blanch, Valencia, 2017, p. 121 y RODRIGUEZ PIÑERO, M., "La saga de Diego Porras: lo que es y lo que no es". Blog: Trabajo, persona, Derecho y Mercado [en línea], [fecha de consulta 30/06/2018]. Disponible en http://grupo.us.es/iwpr/2016/11/29/la-saga-dediego-porras-lo-que-es-y-lo-que-no-es/
} 
En su defecto, se creó una comisión de expertos con el objetivo declarado, pero no implementado finalmente, de tratar de examinar el impacto de las sentencias y formular medidas a adoptar. La comisión puso de relieve que la sentencia Porras no proporciona una respuesta lo suficientemente precisa y que, entre otras cosas incurre en una confusión conceptual al equiparar las "razones objetivas" de la finalización de los contratos de duración determinada ex. artículo 49.1 c) ET, con la extinción por voluntad del empresario basada en causa objetiva prevista en el artículo 52 c) ET. En cualquier caso, y aunque se aportaron soluciones parciales, no se emitieron conclusiones definitivas, fundamentalmente por estar pendientes de pronunciamiento otros asuntos sobre el tema debatido, y por entender necesario esperar a su resolución para no provocar decisiones normativas que pudieran chocar con las resoluciones tanto del Tribunal Supremo (TS) como del TJUE?

Ahora bien, quienes no se detuvieron fueron un buen número de jueces y tribunales que han aplicado lo declarado en las sentencias. Y lo han hecho en sentidos opuestos ${ }^{8} \mathrm{e}$ incluso más allá del contrato de interinidad ${ }^{9}$. Por ejemplo, una parte de ellos han entendido que nada impide la aplicación extensiva (aunque no automática) de la STJUE de Diego Porras a otras modalidades de contratos de duración determinada, tanto del sector público como privado, concluyendo que no resulta ajustado a derecho indemnizar de forma desigual a los fijos respecto de los temporales comparables cuando se produce el cese por causas objetivas, reconociendo la indemnización de 20 días de salario ${ }^{10}$. En otros supuestos, no han entendido que sea aplicable esta doctrina, por ejemplo, a las relaciones entre particulares, esencialmente, por carecer la Directiva 99/70 de eficacia directa horizontal ${ }^{11}$.

\footnotetext{
${ }^{7}$ Vid., "Conclusiones provisionales del grupo de expertos sobre la STJUE 14.9.2016, Caso de Diego Porras"

${ }^{8}$ En profundidad, PÉREZ ReY, J., "El asunto Porras en la doctrina judicial: recorrido por las primeras sentencias aplicativas de la STJUE 14.9.2016, C-596/14", Trabajo y Derecho, n 28, 2017, pp. 83-92.

${ }^{9}$ La denominada "tesis maximalista" o "efecto expansivo". Así, Molina NAVARrete, C., El empleo temporal en el laberinto judicial: desenmarañando el enredo, op. cit., p. 39 y ss.

${ }^{10}$ En este sentido, sentencias del TSJ País Vasco de 18.10.2016 (rec. 1690/2016 y rec. 1872/2016); del TSJ Extremadura de 21.3.2017 (rec. 37/2017) y del TSJ Cataluña de 31.7.2017 (rec. 2190/2017) que se unen a la del TSJ Madrid de 5.10.2016 (res. 613/2016), que recibe la respuesta del caso Porras pero que no es firme por haber sido impugnada a través de recurso de casación presentado por la Abogacía del Estado.

${ }^{11}$ En este sentido, la STSJ Madrid de 11.5.2017 (rec. 113/2017) respecto al no reconocimiento de la indemnización de los 20 días en los contratos por obra o servicio y la STSJ Andalucía (Málaga) de 16.11.2016 (rec. 1539/2016) que entiende que la Directiva 99/70 no tiene efecto directo horizontal, declarando que el tratamiento diferente entre fijos y temporales no puede considerarse una discriminación en sentido propio, ni que tampoco cabe efectuar una interpretación conforme del artículo 49.1 c ET., en relación con el supuesto que la misma analiza dados los términos claros y contundentes que fijan la indemnización correspondiente al cese del contrato temporal en 12 días por año de servicio.
} 
En resumen, un desconcierto interpretativo e inseguridad jurídica consecuencia de una resolución imprecisa, y también del incumplimiento de lo dispuesto en la Directiva 99/70 por parte del Reino de España que, como advierte Preciado, no es algo puntual o que pueda considerarse de anecdótico ${ }^{12}$. Más bien al contrario; resulta, junto con el uso patológico de la temporalidad en la contratación laboral, algo estructural que, conviene destacarlo y reiterarlo, es preocupante y precisa de una reforma legal urgente ${ }^{13}$

La encargada de resolver la controversia hermenéutica, la Sala IV del TS, incomoda y dubitativa, decidió presentar nueva cuestión prejudicial solicitando a través del auto de 25 de octubre de 2017, rec. 3970/2016, que clarificase su sentencia de 14 de septiembre de 2016. Solicitud que se unió a otras cuestiones prejudiciales iniciadas, entre otros, por el TSJ Galicia (auto de 7 de noviembre de 2016) y por el Juzgado de lo Social (JS) n 33 de Madrid (auto de 21 de diciembre 2016) ya resueltas y que se analizan en el presente artículo, junto con otras 12 nuevas cuestiones prejudiciales pendientes de respuesta sobre distintas situaciones jurídicas conectadas, directa o indirectamente con la contratación temporal en España y la doctrina derivada de la STJUE de Diego Porras.

En este trabajo se realiza un breve comentario de las sentencias Grupo Norte Facility, asunto C-574/16, y Lucía Montero Mateos, asunto C-677/16. En ellas, el TJUE (reunido en Gran Sala) viene a retractarse de lo dispuesto en las sentencias anteriores. Entienden los miembros del Tribunal de Luxemburgo que el principio de no discriminación contenido en la clausula $4^{\text {a }}$, apartado 1 de la Directiva $99 / 70^{14}$ no se opone a las diferencias en las cuantías indemnizatorias previstas en la norma española, en concreto del contrato indefinido extinguido por causas objetivas, respecto del contrato de relevo y del contrato de interinidad finalizado por razones objetivas al tener, una previsibilidad, una finalidad y un contexto distinto. ¿Cambio definitivo de doctrina?, ¿rectificación inducida?, ¿interpretación ajustada a derecho?; estas son algunas de las cuestiones objeto de debate.

\footnotetext{
${ }^{12}$ Preciado Domenech, C. H., La contratación temporal tras las SSTJUE de 14 de septiembre de 2016. Los casos de Diego Porras, Pérez López y Martínez Andrés, Editorial Bomarzo, Albacete, 2016, p. 72

${ }^{13}$ Cfs., Rodriguez-PiÑERo, M. y CASAS BAAMONDE, M. E., "La igualdad de trato en la contratación temporal, el derecho de los trabajadores interinos a indemnización por finalización de su contrato por causa objetiva y los encadenamientos abusivos de contratos y relaciones de servicios temporales en las Administraciones públicas españolas. Las sentencias del Tribunal de Justicia de la UE de 14 de septiembre de 2016", Derecho de las Relaciones Laborales, n 9, 2016, p. 871.

14 "Por lo que respecta a las condiciones de trabajo, no podrá tratarse a los trabajadores con contrato de duración determinada de una manera menos favorable que los trabajadores fijos comparables por el mero hecho de tener un contrato de duración determinada, a menos que se justifique un trato diferente por razones objetivas".
} 


\section{Marco legal, controversias suscitadas y las resoluciones del TJUE}

De forma somera, conviene recordar que el marco jurídico nacional sobre el que se proyectan los asuntos a los que haremos referencia, lo encontramos en los artículos 12.6, 12.7, 15, 49.1, 52, y 53.1 b) del Estatuto de los Trabajadores (ET) y en los artículos, 4 y 8 del Real Decreto 2720/1998, de 28 de diciembre, por el que se desarrolla el artículo 15 del Estatuto de los Trabajadores en materia de contratos de duración determinada. Sin ser el objeto principal de análisis de este comentario, a ellos nos remitimos pues, no está de más recordarlo, este marco regulador debería cumplir con todo lo dispuesto en la Directiva 99/70 y, específicamente respecto al régimen extintivo de los contratos de duración determinada, con las cláusulas 4 (prohibición de discriminación) y 5 (prohibición de abuso). Sin embargo, la numerosa litigiosidad en la materia muestra otra realidad.

\subsection{Asunto Grupo Norte Facility (C-574/16)}

a. Los hechos enjuiciados

El supuesto que da origen a la controversia es el siguiente: el Sr. Moreira Gómez prestó servicios desde noviembre de 2012 como peón de limpieza en el Hospital Montecelo de Pontevedra para la empresa Grupo Norte mediante un contrato de trabajo celebrado para sustituir a una trabajadora (su madre) que accedió a la situación de jubilación parcial, reduciendo su jornada y salario en un $75 \%$. El contrato fijaba una finalización con fecha 18 de septiembre de 2015, momento en el que la trabajadora relevada accedería a la jubilación total.

En la fecha prevista, Grupo Norte comunicó la extinción de la relación laboral al Sr. Moreira Gómez quien interpuso ante el JS n ${ }^{\circ} 2$ de Pontevedra demanda por despido. El Juzgado declaró la improcedencia de la extinción y condenó a la readmisión o el abono de la indemnización correspondiente. La empresa recurrió en suplicación ante el TSJ de Galicia que decidió suspender el procedimiento y plantear procedimiento prejudicial ante el TJUE preguntando, en esencia, si constituye una desigualdad de trato entre temporales e indefinidos la diferencia indemnizatoria por extinción del contrato de trabajo por circunstancias objetivas (12 días ex. artículo 49.1 c) ET.) y la derivada de causas objetivas (20 días ex. artículo 52 ET) cuando no se está en presencia de un despido improcedente. Y si, en relación con los principios de igualdad de trato y no discriminación, esta desigualdad de trato en la indemnización por extinción contractual contemplada en la norma española, constituye una discriminación de las prohibidas en el artículo 21 de la Carta de Derechos Fundamentales de la Unión Europea (CDFUE). 


\section{b. La respuesta a la controversia}

El Alto Tribunal, en sus apartados 38 y 39, responde al fondo del asunto recordando que la cláusula $4^{\mathrm{a}}$ del Acuerdo Marco expresa un principio de Derecho social de la Unión que no puede ser interpretado de manera restrictiva ${ }^{15}$ y que esta cláusula incluye una prohibición de tratar, por lo que respecta a las condiciones de trabajo, de manera menos favorable a los trabajadores temporales que a los fijos comparables, a menos que se justifique el trato diferente por razones objetivas.

A partir de ahí considera, primero, que el Sr. Moreira Gómez es un trabajador con contrato de duración determinada, en el sentido de la cláusula 3, apartado 1, del Acuerdo Marco. Segundo, que la indemnización por extinción del contrato de trabajo controvertida en el litigio forma parte de las denominadas "condiciones de trabajo" a las que se hace referencia en la cláusula $4^{\mathrm{a}}$, apartado 1 del Acuerdo Marco ${ }^{16}$, recordando además en su apartado 46 que el principio de no discriminación "exige que no se traten de manera diferente situaciones comparables y que no se traten de manera idéntica situaciones diferentes, a no ser que dicho trato esté objetivamente justificado". En tercer lugar, si bien emplaza al Tribunal remitente a determinar si el trabajador se encontraba en una situación comparable a la de los trabajadores indefinidos, reconoce que la situación del actor, con contrato de duración determinada (relevo), era comparable a la de un trabajador fijo para ejercer las mismas funciones pues ocupaba el mismo puesto que la trabajadora relevada.

Llegados a este punto, el TJUE examina la existencia de razón objetiva que justifique la diferencia de trato contemplada en la norma española por la que, el trabajador con contrato temporal de relevo que ve extinguido su contrato de trabajo por causa prefijada, recibe una indemnización inferior que la que percibe un trabajador fijo cuando finaliza su relación laboral por circunstancias sobrevenidas e imprevistas. Y es aquí donde se

\footnotetext{
${ }^{15}$ Según sentencias del TJUE de 22.12.2010, Gavieiro Gavieiro e Iglesias Torres, asuntos acumulados C444/09 y C-456/09 (apartado 49); de 13.3.2014, Nierodzik, asunto C-38/13 (apartado 24) y de 13.9.2007, Del Cerro Alonso, asunto C-307/05 (apartado 38).

${ }^{16}$ El TJUE ya se había pronunciado con claridad sobre la inclusión de la indemnización por cese como una condición de trabajo comprendida en el ámbito de aplicación del principio de no discriminación, en concreto, en la sentencia de 16.2.1982, Burton, asunto C-19/81 (apartado 9), en la sentencia de 10.6.2010, Bruno y otros, asuntos acumulados C-395/08 y C-396/08 (apartado 46) y en la propia sentencia de Diego Porras (apartado 31). Por otra parte, el artículo 3.1 c) de la Directiva 2000/78, relativa al establecimiento de un marco general para la igualdad de trato en el empleo y la ocupación, establece de forma inequívoca que las condiciones de trabajo incluyen, particularmente, las condiciones de despido. Igualmente, en el artículo 14.1 c) de la Directiva 2006/54/CE, relativa a la aplicación del principio de igualdad de oportunidades e igualdad de trato entre hombres y mujeres en asuntos de empleo y ocupación.
} 
encuentra la principal diferencia respecto a lo dispuesto en la doctrina Porras pues el Tribunal entiende que concurre razón objetiva para el trato desigual.

La Gran Sala acoge la argumentación del Gobierno español que señala que, la diferencia indemnizatoria, está basada en el contexto en que se produce la extinción de los contratos. Así, mientras la indemnización de 20 días prevista en el artículo 53.1 b) ET viene a compensar el cese imprevisto del contrato de trabajo por la concurrencia de alguna de las causas del artículo 52 c) ET, la indemnización del artículo 49.1 c) ET (introducida para prevenir el empleo temporal excesivo y reforzar la estabilidad en el empleo), no tiene por objeto compensar la frustración por la pérdida del empleo debido a que, desde su inicio, se conoce la duración limitada de este ${ }^{17}$.

Sobre estas premisas, el Tribunal advierte en su apartado 56 que la extinción del contrato de relevo se desarrolló "en un contexto sensiblemente diferente, desde los puntos de vista fáctico y jurídico" respecto de aquellos contratos de duración indefinida que se extinguen de forma inesperada por causas económicas, técnicas, organizativas o de producción. El Sr. Moreira Gómez conocía, desde el momento de la celebración, el acontecimiento que determinaría el término de la relación laboral: la jubilación de la trabajadora relevada ${ }^{18}$. Concluye, en esencia, que el contrato de relevo, donde la fecha o acontecimiento que pone fin a la relación laboral es previsible, y donde además concurren objetivos legítimos de política social (fomento de empleo), la diferencia de trato indemnizatorio respecto a los trabajadores con contrato de duración indefinida que extinguen su contrato por una causa objetiva, es lícita y conforme con la cláusula $4^{\mathrm{a}}$, apartado 1 del Acuerdo Marco por constituir, la finalidad específica de las indemnizaciones previstas en la norma española, una razón objetiva el trato diferenciado.

\subsection{Asunto Montero Mateos (C-677/16)}

a. Supuesto de hecho

En este caso, con perspectivas de hacerse tan conocido como la STJUE de Diego Porras, los hechos son los siguientes: la Sra. Montero Mateos prestó servicios desde el 13 de marzo 2007 como auxiliar de hostelería en una residencia de personas mayores

\footnotetext{
${ }^{17}$ Cfs., Sentencia del TJUE de 5.6.2018, Grupo Norte Facility, asunto C-574/16 (apartado 55).

${ }^{18}$ En el apartado 59 de la sentencia, a diferencia de lo que ocurrió en la sentencia de Diego Porras, el TJUE aclara que, en el ordenamiento legal español, ante situaciones de cese del trabajador por causas objetivas ex. artículo 52 ET., no existe ninguna diferencia de trato entre trabajadores con contrato de duración determinada y trabajadores fijos comparables, porque el articulo 53.1b) ET establece el abono de una indemnización de veinte días de salario con independencia de la duración temporal o indefinida del contrato de trabajo.
} 
dependiente de la Agencia Madrileña de Atención Social de la Consejería de Políticas Sociales y Familia de la Comunidad Autónoma de Madrid, formalizando la relación laboral mediante un contrato de interinidad para sustituir a un trabajador fijo. Este contrato fue transformado con fecha 1 de febrero 2008 a interinidad por vacante. El 3 de octubre de 2009 se convocó un proceso extraordinario para la consolidación del puesto, adjudicándose la plaza a otra persona. Por este motivo, el 30 de septiembre de 2016 se extinguió el contrato de interinidad que tuvo una duración total de 9 años y 6 meses [sic].

La trabajadora interpuso demanda por despido el 14 de octubre de 2016 ante el JS n 33 de Madrid que, ante las dudas más que razonables en relación la aplicación de la doctrina Porras y el régimen indemnizatorio ${ }^{19}$, planteó la siguiente pregunta ante el TJUE: ¿es contrario a la Cláusula $4^{\text {a }}$, apartado 1 de la Directiva 99/70 que la norma nacional no prevea indemnización alguna para la extinción del contrato temporal de interinidad por la cobertura de la vacante, mientras que prevé indemnización de 20 días por año en supuestos de extinción del contrato de un trabajador fijo comparable que ha sido despedido por causa objetiva?

\section{b. La respuesta del TJUE}

Al igual que en su apreciación sobre el asunto Grupo Norte, se declara que la norma española es conforme con el Acuerdo Marco y que no existe discriminación, en este caso, del personal interino respecto al personal indefinido o fijo comparable. Para llegar a esta conclusión, el Tribunal de Luxemburgo, siguiendo la doctrina Porras, confirma en su respuesta a la cuestión prejudicial, primero, que la relación laboral de duración determinada era lícita (apartado 43); segundo, que una indemnización como la controvertida en el litigio principal es una condición de trabajo (apartado 48); tercero, que las diferencias de trato alegadas afectaban a trabajadores con contrato de duración determinada respecto de trabajadores con contrato indefinido, no entre temporales

\footnotetext{
${ }^{19}$ En la cuestión prejudicial se afirma que la sentencia de Diego Porras ha llevado a los tribunales españoles a conceder a los trabajadores interinos, "la misma indemnización que la que se otorga, en particular, a los trabajadores fijos comparables por la extinción de sus contratos debido a la concurrencia de una de las causas previstas en el articulo 52 del Estatuto de los Trabajadores", sin embargo, señala también que la sentencia no aclara si el hecho de tener conocimiento de la duración limitada del contrato, justifica, respecto a las indemnizaciones por extinción de la relación laboral, un trato diferente respecto de los trabajadores fijos que extinguen su contrato por alguna de las causas previstas en el artículo 52 ET. Cfs., Sentencia del TJUE de 5.6.2018, Lucía Montero Mateos, asunto C$677 / 16$ (apartados 28 y 30 ).
} 
(apartado 52) y, cuarto, que la situación de la trabajadora en cuestión era comparable a la de los trabajadores contratados por tiempo indefinido ${ }^{20}$.

Ahora bien, como sucede en la sentencia anteriormente reseñada, el TJUE censura el razonamiento más significativo de la doctrina Porras y estima que existe razón objetiva que justifica el diferente trato indemnizatorio entre temporales e indefinidos previsto en la disposición nacional ex. artículos 49.1 c y 53.1 b ET: el trabajador que firma un contrato de duración determinada por interinidad es consciente, desde el inicio de la relación laboral, de la limitación temporal de esta ${ }^{21}$, mientras que en la extinción de un trabajador fijo a instancias del empresario, el trabajador debe ser compensado por resultar inesperada la situación o, como declara el Tribunal, imprevista la causa sobrevenida que pone fin al contrato de trabajo ${ }^{22}$ y ver frustradas sus expectativas de estabilidad en el empleo.

A pesar de esto, el Tribunal deja la puerta abierta para recalificar la relación laboral y aunque no lo incorpora al fallo de la sentencia, en su apartado 64 señala que la trabajadora no podía conocer, en el momento en que se celebró su contrato de interinidad, la fecha exacta en que se aprovisionaría el puesto que ocupaba con carácter definitivo, ni tampoco que dicho contrato tendría una duración 'inusualmente larga'. De modo que se remite al juzgado que planteó la cuestión prejudicial invocándole a examinar si, debido a la indeterminación de la fecha previsible de finalización del contrato y su dilatada duración, debería ser recalificado como contrato fijo.

\section{Valoración de la fundamentación y sus efectos inmediatos}

Resulta evidente; las sentencias objeto del presente comentario dan un giro doctrinal relevante en relación con el asunto Porras. Aunque confirman la mayoría de sus posicionamientos, estos son, que la indemnización por finalización es una condición de trabajo, que las diferencias de trato lo son exclusivamente entre trabajadores con contrato de duración determinada e indefinidos (no entre temporales), y que la situación en relación con el trabajo prestado y las funciones desempeñadas es comparable, lo cierto es que contradicen el argumento más significativo contenido en la sentencia de 14

\footnotetext{
${ }^{20}$ Extremo incontrovertido pues las tareas realizadas en supuestos de contratación por interinidad son, generalmente, las mismas que las de los trabajadores indefinidos que sustituye. Como declara la sentencia en su apartado 53, la actora ejercía las mismas funciones que aquellas para las que fue contratada posteriormente la persona que superó finalmente el proceso extraordinario para proveer la plaza.

${ }^{21}$ Como aclara la abogada general Sra. Juliane Kokott en las conclusiones generales (punto 56) presentadas con fecha 20 de diciembre de 2017 sobre el presente caso, la finalización del contrato era conocida y esperable pues se vinculaba a un acontecimiento futuro acordado en el contrato: la contratación de un trabajador fijo una vez finalizado el proceso selectivo en curso.

${ }^{22}$ Cfs., Sentencia del TJUE de 5.6.2018, Lucía Montero Mateos, asunto C-677/16 (apartado 61).
} 
de septiembre de 2016 pues legitiman las disposiciones nacionales que permiten una diferencia de trato indemnizatorio entre un contrato de duración determinada y otro indefinido.

La Gran Sala del TJUE suscribe que disponer de la información acerca de la fecha prevista de la finalización de la relación laboral, o conocer la condición que permite extinguir el contrato, transforma a esta situación en previsible pues se tiene certeza de la situación en el momento de la celebración del contrato. Previsibilidad que entiende, no concurre cuando se produce un despido por causas objetivas pues se produce de forma sobrevenida e inesperada, frustrándose las expectativas laborales del trabajador.

Con esta exégesis, se rechaza lo dispuesto con carácter principal en la sentencia de Diego Porras, donde se vino a señalar que la clausula $4^{\mathrm{a}}$, apartado 1 del Acuerdo Marco debe interpretarse en el sentido de que se opone a una normativa nacional que deniega cualquier indemnización por finalización de contrato al trabajador con contrato de interinidad concediendo, sin embargo, indemnización a los trabajadores fijos comparables. Entiende ahora el TJUE que la normativa nacional no es discriminatoria cuando contempla una diferencia de trato (en materia indemnizatoria) entre temporales e indefinidos ya que esta obedece a razones objetivas: la finalidad específica de las indemnizaciones (establecidas para cada supuesto atendiendo a causas concretas) y el contexto particular en que se abonan (el carácter previsible o no de la extinción del contrato).

Tanto en la sentencia Grupo Norte como en la sentencia Montero Mateos, se asume este razonamiento, ahora bien, en esta última resolución hay una diferencia sustancial pues el Tribunal lanza un globo sonda o, en palabras de Molina, un "nuevo enigma envuelto en otros enigmas de justicia oracular" 23 al señalar en su apartado 64 que "incumbe al juzgado remitente examinar si, habida cuenta de la imprevisibilidad de la finalización del contrato y su duración, inusualmente larga, ha lugar a recalificarlo como contrato fijo".

Pues bien, la respuesta al mandato no se ha hecho esperar. Con fecha 28 de junio de 2018, el JS n 33 de Madrid, receptor de la respuesta del TJUE, se ha pronunciado. Y lo ha hecho, como no cabía de otro modo, aplicando el ordenamiento y jurisprudencia nacionales. Así, respecto de la imprevisibilidad de la fecha de extinción del contrato de interinidad, recuerda que este contrato no permite conocerla de forma clara y que la

\footnotetext{
${ }^{23}$ Molina NAVARRETe, C., "La indemnización extintiva de los interinos (y demás temporales): ¿fin de la historia o nuevo capítulo sin fin? Comentario a las Sentencias del Tribunal de Justicia de la Unión Europea de 5 de junio de 2018, Montero Mateos (C-677/16) y Grupo Norte Facility (C-574/16)", Estudios financieros. Revista de Trabajo y Seguridad Social, nº 424/2018, p. 7.
} 
actora sabía que la cobertura de la plaza supondría su cese por lo que, el desconocimiento ab initio de la fecha concreta, no puede conducir a calificar el vínculo como fijo ${ }^{24}$. Ahora bien, en relación con la duración excesivamente larga, tras una detallada fundamentación jurídica y un análisis de la doctrina judicial conectada (no pacífica), resuelve, en virtud del principio de interpretación conforme ex. cláusula $5^{\mathrm{a}}$ del Acuerdo Marco, que los contratos de interinidad para cobertura de vacante no pueden exceder del plazo improrrogable de tres años establecido en el artículo 70.1 del Estatuto Básico del Empleado Público (EBEP), que fija esta limitación para la ejecución de ofertas de empleo público. En consecuencia, concluye que, en el asunto Montero, puesto que en plazo señalado no se extinguió el contrato de trabajo por la causa que motivó su formalización (la cobertura reglamentaria de la plaza), deja de ser un contrato temporal y procede su recalificación como indefinido no fijo ${ }^{25}$. En efecto, ante la extinción (asimilable a las causas objetivas contempladas en la norma nacional), concede una indemnización de 20 días $^{26}$.

Con anterioridad a este pronunciamiento, esta doctrina ya había sido acogida parcialmente por el TSJ de Castilla León (Valladolid) que, a partir de una pormenorizada fundamentación con base en las sentencias comentadas en el presente trabajo, pero por motivos legales y jurisprudenciales distintos, reconoce una indemnización de 20 días a una trabajadora interina por vacante. En esencia, por considerar que, aunque la causa de finalización del contrato fue la pactada al inicio (la cobertura de la plaza), la fecha de término resultaba imprevisible y la relación laboral se prolongó de forma inusualmente larga durante más de 7 años ${ }^{27}$.

De la misma forma, y si bien, también asume esta doctrina reconociendo que supera la derivada del caso Porras, la sentencia del TSJ del País Vasco, de 26 de junio de 2018 (rec.1240/2018) relativa al cese de un contrato de obra o servicio formalizado por una ETT, rechaza sin embargo el reconocimiento de la indemnización de 20 días.

\footnotetext{
${ }^{24}$ Cfs., fundamento jurídico séptimo de la Sentencia 260/18 del JS no 33 de Madrid, de 28.6.2018.

${ }^{25}$ Acude el juzgador a la STS de 15.5.2018 (rec. 1717/2015) donde se advierte del origen de la figura del personal indefinido no fijo y de la imposibilidad de calificar como personal fijo los abusos de derecho en la contratación temporal cuando el empleador es la Administración Pública, fundamentalmente, por vulnerar los mecanismos de acceso al empleo público que debe efectuarse a través de concursos públicos en los que se respeten los principios de igualdad, mérito y capacidad.

${ }^{26}$ Según STS de 28.3.2017 (rec. 1664/2015).

27 "Lo que se desprende de la sentencia del Tribunal de Justicia es que debe existir un umbral de duración para aquellos contratos temporales cuya fecha no haya sido fijada con precisión, de manera que traspasado dicho umbral la diferencia de trato indemnizatoria deja de estar justificada y debe abonarse la indemnización por despido objetivo a su finalización". Cfs., fundamento jurídico quinto de la STSJ Castilla y León (Valladolid) de 11.6.2018 (rec. 833/2018).
} 
Habida cuenta de todas las consideraciones anteriores, la sentencia Montero Mateos, asunto C-677/16, tiene probabilidades de hacerse célebre o, en palabras de Beltrán, de haber "iniciado su propia saga" 28 . Fundamentalmente por la vía abierta y, acogida con matices por el Juzgado remitente, acerca de la posible recalificación como trabajadores indefinidos no fijos (con las consecuencias inherentes) que pueda hacerse de los contratos temporales con una duración inusualmente larga ${ }^{29}$. Como ya muestran las diversas respuestas judiciales al respecto, la interpretación de esta doctrina (y sus consecuencias) no es unívoca por lo que el debate esta servido.

\section{Conclusiones: la tormenta continúa}

Abuso de derecho, desigualdad de trato, interpretaciones judiciales creativas. Son solo algunos de los efectos que el sistema español de contratación temporal provoca en la actualidad. Sistema que, alterado significativamente por las resoluciones del TJUE en la materia y su aplicación (ambivalente) ha puesto a uno de los problemas estructurales del mercado de trabajo español en el centro de atención. En un país con una tasa de temporalidad superior al $25 \%$ y donde se estima que 1 de cada 4 contratos temporales están celebrados en fraude de ley, una sentencia como la emitida para el caso Porras hacía previsible los efectos inmediatos en el ámbito judicial, sindical y empresarial: disparidad interpretativa, litigiosidad creciente e inseguridad jurídica.

Si el 14 de septiembre de 2016 las sentencias de Diego Porras, Pérez López y Martínez Andrés, reprobaban a España por la inadecuada transposición y/o aplicación de la Directiva $99 / 70^{30}$, casi dos años después, las sentencias Grupo Norte Facility y Montero Mateos vienen a validarla rectificando su propio criterio que, aunque impreciso, ha sido aplicado por un buen número de jueces y tribunales de forma dispar.

Puede deducirse con ello que, a falta de confirmación por parte del TJUE, que deberá posicionarse en una docena de casos abiertos, el recorrido de la doctrina Porras parece

\footnotetext{
${ }^{28}$ Beltran De Heredia Ruiz, I., "Primeras reacciones al caso Montero Mateos: interinos de larga duración tienen derecho a 20 días de indemnización (TSJ CyL)". Blog: Una mirada crítica a las relaciones laborales [en línea]. Disponible en http://ignasibeltran.com/2018/06/17/primeras-reacciones-al-casomontero-mateos-interinos-de-larga-duracion-tienen-derecho-a-20-dias-de-indemnizacion-tsj-cyl/ [fecha de consulta 30/06/2018]

${ }^{29}$ Molina Navarrete, C., "La indemnización extintiva de los interinos... op. cit., p. 12, "el TJUE no crea ningún cortafuegos respecto al alcance de su doctrina fuera de los contratos de interinidad. Por eso es previsible que se extienda el enigma a otros contratos temporales en los que la práctica nacional evidencia que se producen situaciones análogas de imprevisibilidad del cese por vincularse a acontecimientos (condiciones) no solo inciertos, sino a veces de larga duración relacional".

${ }^{30}$ En profundidad, PRECIADo DoMENECH, C. H., La contratación temporal tras las SSTJUE..., op. cit, p. 11 y ss.
} 
haber finalizado. Las sentencias comentadas confirman gran parte de los puntos enjuiciados, sin embargo, contradicen el elemento clave: la diferencia de trato indemnizatorio entre trabajadores fijos y temporales contenida en la norma española que, para estos casos, la estiman compatible con lo dispuesto en la cláusula $4^{\text {a }}$, apartado 1 del Acuerdo Marco ${ }^{31}$.

Señala el profesor CRUZ que nos encontramos ante "una argumentación más afinada y fundada" que la existente en la STJUE de Diego Porras ${ }^{32}$ no obstante, es incuestionable que también se crean nuevas controversias. En cualquier caso, estas sentencias aclaran determinados aspectos que recapitulamos en los siguientes puntos conclusivos:

- El principio de no discriminación contenido en el Acuerdo Marco no alcanza a las posibles diferencias de trato entre distintas categorías de trabajadores temporales. $\mathrm{Su}$ cláusula $3^{a}$ exige la comparación con un trabajador con contrato de trabajo de duración indefinida comparable.

- La situación de un trabajador de duración determinada es comparable a la de un trabajador fijo cuando la prestación de servicios se produce en el mismo centro de trabajo y cuando se realiza un trabajo idéntico o similar, teniendo en cuenta su cualificación, las condiciones laborales y las tareas desempeñadas.

- Las situaciones de los trabajadores temporales con contrato de relevo o de interinidad son comparables a las de los indefinidos que relevan / cubren porque las tareas que realizan son, por lo general, las mismas.

- Para que exista contratación temporal lícita es necesario que el motivo de finalización del contrato esté vinculado a una fecha o un acontecimiento determinado. Si las circunstancias no permiten conocer $a b$ initio la fecha en la que concurrirá el acontecimiento y/o, además, la duración de la relación resulta “inusualmente larga", podrá ser calificada judicialmente como indefinida no fija.

\footnotetext{
${ }^{31}$ Eso si, los matices del caso Montero han provocado que en el fallo final emitido por el $\mathrm{JS} \mathrm{n}^{\circ} 33$ de Madrid se produzca el mismo resultado indemnizatorio. Así se aclara en su fundamento jurídico décimo sexto: "[t]odo este largo viaje conduce así a una paradoja final consistente en que, desde un punto de vista material, aunque por razones legales y jurisprudenciales distintas, la STJUE caso de Diego Porras y la dictada en este procedimiento por resultar de aplicación al caso controvertido el razonamiento 64 sobre la relevancia de su excesiva y por ello injustificada duración, provocan las mismas consecuencias indemnizatorias".

32 Cruz Villalón, J., "Donde dije digo...”, El País, [en línea], [fecha de consulta 11/07/2018]. Disponible en https://elpais.com/economia/2018/06/05/actualidad/1528224303_962472.html
} 
- No existen diferencias de trato entre trabajadores temporales e indefinidos en presencia de un despido por las causas previstas en el artículo 52 ET. A ambos se les reconoce el abono de una indemnización legal de 20 días.

- La diferencia que justifica el régimen indemnizatorio diferenciado entre trabajadores temporales y fijos ante la extinción por razones objetivas es que, los primeros, conocen desde el inicio de la relación laboral la fecha o acontecimiento que determina su término. Existen por tanto dos tipos de causas objetivas de extinción del contrato: las previstas desde el principio de la relación laboral y las sobrevenidas e inesperadas. Esta diferenciación hace legítima la diferencia en la cuantía indemnizatoria contemplada en la normativa española.

Es fin, el TJUE rectifica su decisión anterior o se desdice de una parte importante de lo señalado en la célebre sentencia de Diego Porras. No obstante, en opinión de quien comenta, las sentencias no son una validación de nuestro sistema de contratación temporal. El problema, es de sobra conocido y, obviamente, no reposa en exclusiva en el régimen indemnizatorio dispar entre indefinidos y temporales. El mayor conflicto se encuentra en el uso indiscriminado y abusivo instalado extraoficialmente en el sistema de relaciones laborales español donde, los contratos de duración determinada, en multitud de casos, se han convertido en la principal vía (precaria) de entrada al mercado de trabajo en el sector privado, o en la terminal de espera (inusualmente larga, siguiendo la expresión del TJUE), por ejemplo, de un buen número de interinos de la Administración Pública que representan, dicho sea de paso, casi el $45 \%$ de los trabajadores con contratos de duración determinada del sector Público ${ }^{33}$.

Este modus operandi permite entender el sistema de contratación laboral en España como un modelo instalado en una especie de 'flexitemporalidad', entendida esta como una característica propia de nuestro mercado de trabajo donde, una de las principales vías implementadas en las sucesivas reformas desde los años 80 , ha sido la flexibilidad externa (empleadas por las empresas para responder a los ciclos económicos) a partir del uso intensivo de la contratación temporal y sus bajos (o nulos) costes de extinción.

Una reforma legal del sistema es necesaria. Las propuestas políticas, sindicales y académicas pueden ayudar en esta tarea ${ }^{34}$. Mientras tanto, permaneceremos atentos a las

\footnotetext{
${ }^{33}$ De los 762.100 trabajadores con contratos de duración determinada al servicio de las Administración Públicas en el primer trimestre del año 2018, alrededor de 331.200 lo hacían bajo un contrato de interinidad por sustitución. Vid., Encuesta de Población Activa (EPA) 1T-2018, Asalariados del sector público por tipo de contrato o relación laboral, sexo y grupo de edad. Instituto Nacional de Estadística (INE), [en línea], [fecha de consulta 11/07/2018]. Disponible en http://www.ine.es/prensa/epa_prensa.htm ${ }^{34}$ Con fecha 13 de julio de 2018 se admitió a trámite la Proposición de Ley contra la precariedad y la estabilidad en el empleo presentada por el Grupo Parlamentario Confederal de Unidos Podemos-En Comú
} 
esperadas y, quizá, de nuevo contradictorias resoluciones judiciales que nos permitan seguir profundizando en la materia y aprendiendo de nuestros errores.

\section{Bibliografía}

Gómez Abelleira, F. J., Contratos laborales y temporalidad. La política legislativa de contratación laboral, Tirant lo Blanch, Valencia, 2017

Molina NAVARrete, C., "La indemnización extintiva de los interinos (y demás temporales): ¿fin de la historia o nuevo capítulo sin fin? Comentario a las Sentencias del Tribunal de Justicia de la Unión Europea de 5 de junio de 2018, Montero Mateos (C677/16) y Grupo Norte Facility (C-574/16)", Estudios financieros. Revista de Trabajo y Seguridad Social, no 424/2018

Molina Navarrete, C., El empleo temporal en el laberinto judicial: desenmarañando el enredo. Estudio de la doctrina judicial española aplicativa de la "trilogía" de Sentencias del TJUE de 14 de septiembre de 2016, Sepim, 2016.

PÉREZ REY, J., "Por una reformulación de nuestro modelo de contratación temporal: reflexiones sobre las consecuencias de la sentencia Porras en nuestro ordenamiento y la eficacia de la Directiva 99/70", Revista de Derecho Social, no 76, 2016, pp. 219-262.

PÉREZ ReY, J., "El asunto Porras en la doctrina judicial: recorrido por las primeras sentencias aplicativas de la STJUE 14-09-2016, C-596/14", Trabajo y Derecho, $\mathrm{n}^{\circ} 28$, 2017, pp. 83-92.

PRECIAdo Domenech, C. H., La contratación temporal tras las SSTJUE de 14 de septiembre de 2016. Los casos de Diego Porras, Pérez López y Martínez Andrés, Bomarzo, Albacete, 2016

Rodríguez-PiÑERo, M. y CASAS BAAMONDE, M. E., "La igualdad de trato en la contratación temporal, el derecho de los trabajadores interinos a indemnización por finalización de su contrato por causa objetiva y los encadenamientos abusivos de contratos y relaciones de servicios temporales en las Administraciones públicas

Podem-En Marea, en la que han colaborado académicos y profesores universitarios expertos en la materia. En relación con lo tratado en este comentario, hay que destacar que esta propuesta establece la posibilidad de sancionar la contratación temporal irregular con la nulidad del contrato, circunstancia que, de llevarse a cabo, garantizaría la tutela de la estabilidad en el empleo frente al fraude o abuso de la contratación temporal. 
españolas. Las sentencias del Tribunal de Justicia de la UE de 14 de septiembre de 2016", Derecho de las Relaciones Laborales, $\mathrm{n}^{\circ}$ 9, 2016, pp. 838-872. 